\title{
Penerapan Planned Maintenance untuk Mereduksi Downtime Mesin MOJ-3 di Departemen Finishing PT. XYZ
}

\author{
Naufal Fadhillah Avrilio*, Nita P. A. Hidayat \\ Prodi Teknik Industri, Fakultas Teknik, Universitas Islam \\ Bandung, Indonesia.
}

*naufalavrilio10@gmail.com, nita.ph@gmail.com

\begin{abstract}
PT. XYZ is a company that produces plastic sacks and warings for local and foreign consumers (exports). This research was conducted at the Finishing Department, which carries out the process of cutting sack rolls into packaged products. There are three series of production processes, namely cutting, sewing, and packing. The process of cutting and sewing is done with the MOJ machine, namely MOJ-1, MOJ-2, and MOJ-3. The MOJ3 engine is the engine that has the highest downtime, which is 409,68 hours. The downtime of the MOJ-3 machine caused the production process to stop because the sacks produced on the MOJ-3 machine could not be transferred to another machine. This research aims to impelement planned maintenance with determine the maintenance intervals to increase machine reliability. Maintenance intervals are specified for conveyor clip components, knife supports, and sewing loopers. The maintenance interval for clip conveyor components is 90 hours, knife support is 72 hours, and the sewing looper is 105 hours. The downtime of the clip conveyor component can be reduced to 19,41 hours, the knife support component to 8,55 hours, and the sewing looper component to 6,17 hours. The calculation results show that joint maintenance with a time interval of 105 hours can reduce the total maintenance cost from Rp207.963.924 (currently) to Rp91.808.815 (proposed).
\end{abstract}

Keywords: Planned Maintenance, Maintenance Interval, Maintenance Cost.

Abstrak. PT. XYZ merupakan perusahaan yang memproduksi karung plastik dan waring kepada distributor lokal dan konsumen luar negeri (ekspor). Penelitian ini dilakukan di Departemen Finishing yang melakukan proses pemotongan gulungan karung hingga menjadi produk yang telah dikemas. Terdapat tiga rangkaian proses produksi, yaitu pemotongan, penjahitan, dan pengepakan. Proses pemotongan dan penjahitan dilakukan dengan mesin MOJ, yaitu MOJ-1, MOJ-2 dan MOJ-3. Mesin MOJ-3 merupakan mesin yang memiliki downtime tertinggi, yaitu 409,68 jam. Downtime mesin MOJ-3 mengakibatkan proses produksi terhenti, karena karung yang diproduksi pada mesin MOJ-3 tidak dapat dipindahkan ke mesin lainnya. Penelitian ini bertujuan untuk menerapkan planned maintenance dengan menentukan interval pemeliharaan agar dapat meningkatkan keandalan mesin. Interval pemeliharaan ditentukan untuk tiga komponen kritis mesin MOJ-3, yaitu clip conveyor, penyangga pisau, dan looper jahit. Hasil perhitungan menunjukkan bahwa interval pemeliharaan komponen clip conveyor sebesar 90 jam, penyangga pisau sebesar $72 \mathrm{jam}$, dan looper jahit sebesar 105 jam. Dengan interval pemeliharaan yang dihasilkan, downtime komponen clip conveyor dapat direduksi menjadi 19,41 jam, komponen penyangga pisau menjadi 8,55 jam, dan komponen looper jahit menjadi 6,17 jam. Hasil perhitungan menunjukkan bahwa pemeliharaan bersama dengan interval waktu 105 jam mampu menurunkan total biaya pemeliharaan dari Rp207.963.924 (saat ini) menjadi Rp91.808.815 (usulan).

Kata Kunci: Planned Maintenance, Interval Pemeliharaan, Biaya Pemeliharaan. 


\section{A. Pendahuluan}

PT. XYZ merupakan salah satu perusahaan yang memproduksi karung plastik dan waring kepada distributor lokal dengan strategi respon permintaan Make To Stock (MTS) dan konsumen luar negeri (ekspor) dengan strategi respon permintaan Make To Order (MTO). Perusahaan ini memiliki dua plant, yaitu plant satu (Departemen Produksi) yang melakukan proses produksi dari biji plastik hingga menjadi gulungan karung dan plant dua (Departemen Finishing) yang melakukan proses pemotongan dan penjahitan gulungan karung hingga menjadi karung yang telah dikemas. Penelitian ini dilakukan di Departemen Finishing.

Rangkaian proses produksi di Departemen Finishing terbagi menjadi tiga bagian, yaitu pemotongan, penjahitan, dan pengepakan. Proses pemotongan dan penjahitan dilakukan menggunakan MOJ, sedangkan proses pengepakan dilakukan dengan mesin MOT. Terdapat enam buah mesin MOJ yang digunakan, yaitu mesin MOJ-1, MOJ-2, MOJ-3 yang digunakan untuk memproduksi pesanan ekspor dan mesin MOJ-4, MOJ-5 dan MOJ-6 yang digunakan untuk memproduksi pesanan konsumen lokal.

Kondisi aktual di PT. XYZ memperlihatkan bahwa mesin yang digunakan sering mengalami kerusakan. Berdasarkan data tahun 2017 - 2019, terdapat kerusakan pada mesin MOJ bagian ekspor sehingga mengakibatkan downtime. Saat ini, PT. XYZ tidak memiliki jadwal pemeliharaan dan hanya akan melakukan perbaikan ketika mesin mengalami kerusakan. Data downtime mesin MOJ bagian ekspor Departemen Finishing PT. XYZ ditunjukkan pada Tabel 1.

Tabel 1. Downtime Departemen Finishing Periode Agustus 2017 - Desember 2019

\begin{tabular}{|c|c|c|c|c|}
\hline No & Jenis Mesin & Downtime (jam) & Jam Kerja (jam) & \% Downtime \\
\hline 1 & MOJ-1 & 105,12 & 15.120 & 0,695 \\
\hline 2 & MOJ-2 & 133,92 & 15.120 & 0,886 \\
\hline 3 & MOJ-3 & 409,68 & 15.120 & 2,710 \\
\hline
\end{tabular}

Sumber: Departemen Finishing PT. XYZ, 2020.

Tingginya downtime pada mesin MOJ-3 mengakibatkan proses produksi terhenti, karena karung yang diproduksi pada mesin MOJ-3 tidak dapat dipindahkan ke mesin lainnya. Jika mesin tersebut berhenti, maka jumlah produk yang harus dipenuhi pada waktu yang ditargetkan oleh perusahaan tidak dapat terpenuhi. Kerusakan pada mesin MOJ-3 juga mengakibatkan kecacatan. Data kecacatan karung yang disebabkan oleh kerusakan mesin MOJ bagian ekspor ditunjukkan pada Tabel 2. 
Tabel 2. Jumlah Kecacatan Produk Periode Agustus 2017 - Desember 2019

\begin{tabular}{|c|c|c|c|c|c|c|c|c|c|}
\hline \multirow[b]{3}{*}{ Tahun } & \multicolumn{9}{|c|}{ Mesin } \\
\hline & \multicolumn{3}{|c|}{ MOJ-1 } & \multicolumn{3}{|c|}{ MOJ-2 } & \multicolumn{3}{|c|}{ MOJ-3 } \\
\hline & $\begin{array}{l}\text { Jumlah } \\
\text { Produksi } \\
\text { (lembar) }\end{array}$ & $\begin{array}{c}\text { Jumlah } \\
\text { Cacat } \\
\text { (lembar) }\end{array}$ & $\begin{array}{c}\% \\
\text { Cacat }\end{array}$ & $\begin{array}{l}\text { Jumlah } \\
\text { Produksi } \\
\text { (lembar) }\end{array}$ & $\begin{array}{c}\text { Jumlah } \\
\text { Cacat } \\
\text { (lembar) }\end{array}$ & $\begin{array}{c}\% \\
\text { Cacat }\end{array}$ & $\begin{array}{l}\text { Jumlah } \\
\text { Produksi } \\
\text { (lembar) }\end{array}$ & $\begin{array}{c}\text { Jumlah } \\
\text { Cacat } \\
\text { (lembar) }\end{array}$ & $\begin{array}{c}\% \\
\text { Cacat }\end{array}$ \\
\hline 2017 & 244880 & 5180 & 2,12 & 242960 & 4900 & 2,02 & 267810 & 14430 & 5,39 \\
\hline 2018 & 583704 & 11544 & 1,98 & 581904 & 9888 & 1,70 & 603168 & 58368 & 9,68 \\
\hline 2019 & 582456 & 10416 & 1,79 & 576096 & 10296 & 1,79 & 595056 & 88248 & 14,83 \\
\hline
\end{tabular}

Sumber: Departemen Finishing PT. XYZ, 2020

Berdasarkan latar belakang yang telah diuraikan, maka perumusan masalah dalam penelitian ini yaitu penentuan interval pemeliharaan yang dapat mereduksi downtime pada mesin MOJ-3 di Departemen Finishing PT. XYZ dan menentukan rencana pemeliharaan berdasarkan total biaya pemeliharaan yang terkecil. Adapun tujuan dalam penelitian ini adalah:

1. Menentukan interval pemeliharaan yang dapat mereduksi downtime pada mesin MOJ-3 di Departemen Finishing PT. XYZ.

2. Menentukan rencana pemeliharaan mesin MOJ-3 berdasarkan total biaya pemeliharaan yang terkecil.

3. Membandingkan performansi (downtime dan biaya pemeliharaan) sebelum dan setelah penerapan planned maintenance.

4. Penerapan planned maintenance untuk menentukan interval waktu pemeliharaan dapat dilakukan dengan metode Reliability Centered Maintenance (Rachman, Garside, dan Kholik, 2017) dan (Asisco, Amar, dan Perdana, 2012) atau teori Reliability dan Model Age Replacement (Ruchiyat, Prasetyaningsih, dan Muhammad, 2020).

\section{B. Metodologi}

Planned Maintenance meupakan jenis pemeliharaan yang terorganisir dan dilakukan sesuai pencatatan dan pemikiran ke masa depan (Agustiady dan Cudney, 2016). Menurut Dhillon (2002), pemeliharaan merupakan kombinasi tindakan yang sesuai untuk mempertahankan suatu barang atau peralatan untuk mengembalikan ke kondisi tertentu.

Langkah awal yang dilakukan untuk melakukan pemeliharaan mesin adalah mengidentifikasi komponen kritis yang menjadi penyebab kerusakan menggunakan diagram Pareto. Diagram Pareto adalah diagram yang mempresentasikan urutan prioritas masalah yang terdapat pada sebuah perusahaan atau organisasi, sehingga dapat diketahui masalah mana yang menjadi prioritas utama untuk segera diselesaikan (Heizer dan Render, 2011). Komponen kritis ditentukan berdasarkan frekuensi kerusakan yang tertinggi.

Berdasarkan hasil identifikasi komponen kritis, dilakukan perhitungan Time to Failure (TTF) dan Time to Repair (TTR). TTF adalah selang waktu kerusakan setelah diperbaiki hingga terjadi kerusakan berikutnya, sedangkan TTR adalah lamanya waktu perbaikan hingga mesin dapat berfungsi kembali (Picknell dan Sifonte, 2017). Nilai TTF dan TTR selanjutnya akan digunakan untuk menghitung index of fit $(r)$ menggunakan empat jenis distribusi kerusakan, yaitu normal, lognormal, eksponensial, dan Weibull.

Distribusi kerusakan merupakan sebuah informasi yang berkaitan dengan umur pakai suatu mesin atau peralatan. Data kerusakan setiap mesin perlu diidentifikasi jenis distribusinya. Hal ini bertujuan untuk memudahkan dalam melakukan perhitungan dan penjadwalan interval pemeliharaan mesin (Ebeling, 2019). Tahapan identifikasi distribusi 
kerusakan menghasilkan praduga terhadap data yang diperoleh dengan karakteristik suatu distribusi.

Praduga data terhadap suatu karakteristik distribusi tertentu perlu dibuktikan kecocokannya. Maka, dilakukan uji keocokan distribusi (goodness of fit test) untuk meyakinkan hasil identifikasi distribusi kerusakan terpilih dengan memenuhi hipotesa yang ada. Uji kecocokan distribusi normal dan lognormal dilakukan menggunakan Kolmogorov-Smirnov Test, distribusi eksponensial menggunakan Bartlett's Test, serta distribusi Weibull menggunakan Mann's Test (Ebeling, 2019).

Uji goodness of fit akan menghasilkan distribusi terpilih sesuai dengan syarat hipotesa yang ada. Masing-masing distribusi kerusakan memiliki parameter, sehingga parameter tersebut akan digunakan untuk menentukan nilai Mean Time to Failure (MTTF) dan Mean Time to Repair (MTTR). MTTF adalah rata-rata selang waktu hingga terjadi kerusakan. Sedangkan MTTR menunjukkan rata-rata waktu untuk melakukan perbaikan mesin agar dapat digunakan kembali.

Interval pemeliharaan mesin ditentukan berdasarkan tingkat keandalan yang diharapkan. Keandalan (reliability) merupakan suatu kemungkinan mesin melaksanakan fungsinya untuk periode waktu tertentu (Dhillon, 2002). Semakin tinggi keandalan suatu sistem, maka akan mengurangi kemungkinan terjadinya kerusakan. Jika kerusakan berkurang, maka downtime akan tereduksi.

Kegiatan pemeliharaan tentunya membutuhkan biaya, seperti biaya teknisi, biaya kehilangan produksi (production loss), dan biaya komponen. Pada penelitian ini, perhitungan biaya dilakukan berdasarkan dua kondisi, yaitu failure cost dan preventive cost. Failure cost merupakan biaya yang dikeluarkan karena mesin rusak diluar dugaan (breakdown). Sedangkan preventive cost merupakan biaya untuk melakukan pemeliharaan mesin yang telah terjadwal (Soesetyo dan Bendatu, 2014). 


\section{Hasil dan Pembahasan}

\section{Penentuan Komponen Kritis Mesin MOJ-3}

Terdapat beberapa jenis kerusakan yang mengakibatkan downtime. Kerusakan tersebut berasal dari komponen mesin, sehingga perlu dilakukan perbaikan atau penggantian. Tabel 3 menunjukkan jenis kerusakan, komponen yang mengalami kerusakan, dan frekuensi kerusakannya.

Tabel 3. Jenis Kerusakan Serta Komponen yang Mengalami Kerusakan

\begin{tabular}{|c|c|c|c|}
\hline No. & Jenis Kerusakan & $\begin{array}{c}\text { Komponen yang } \\
\text { mengalami kerusakan }\end{array}$ & $\begin{array}{c}\text { Frekuensi } \\
\text { Kerusakan }\end{array}$ \\
\hline 1 & Penyangga pisau lepas & Penyangga pisau & 80 \\
\hline 2 & Roller cutter macet & Roller cutter & 65 \\
\hline 3 & Rolling pin macet & Rolling pin & 51 \\
\hline 4 & Looper jahit error & Looper jahit & 70 \\
\hline 5 & Clip conveyor error & Clip conveyor & 82 \\
\hline 6 & Conveyor macet & Conveyor & 65 \\
\hline 7 & Sensor ukuran error & Sensor ukuran & 44 \\
\hline 8 & Sensor gulungan error & Sensor gulungan & 55 \\
\hline
\end{tabular}

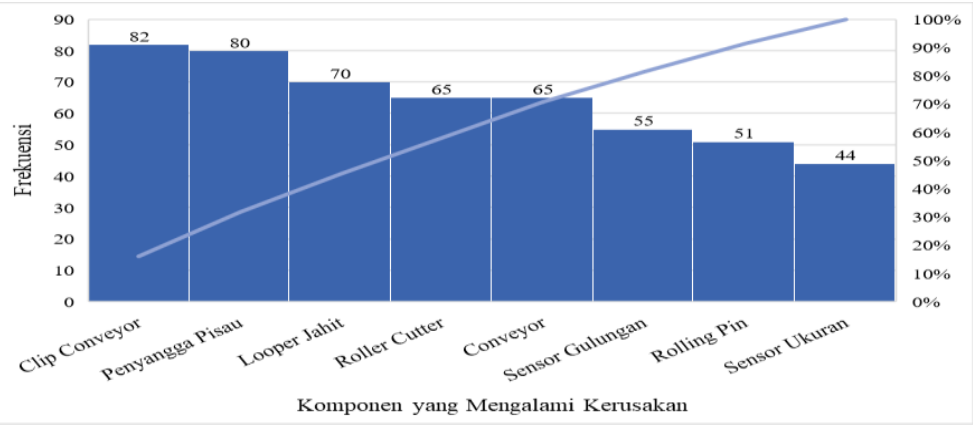

Gambar 1. Diagram Pareto Frekuensi Kerusakan Komponen Mesin MOJ-3

\section{Identifikasi Distribusi TTF dan TTR}

Tahap identifikasi distribusi untuk data TTF dan TTR dilakukan dengan menghitung index of fit menggunakan metode least square curve fitting. Nilai index of fit berada pada rentang antara 0 sampai 1 yang menunjukkan hubungan antara variabel $x$ terhadap variabel $y$. Identifikasi dilakukan menggunakan empat jenis distribusi kerusakan, yaitu distribusi normal, lognormal, eksponensial, dan Weibull. Identifikasi distribusi bertujuan untuk mencari tahu karakteristik data dengan suatu distribusi. Hasil identifikasi distribusi TTF dan TTR ditunjukkan pada Tabel 4.

Tabel 4. Rekapitulasi Index of Fit TTF dan TTR

\begin{tabular}{|c|c|c|c|c|c|}
\hline \multicolumn{2}{|c|}{ Index of Fit } & \multicolumn{4}{c|}{ Distribusi } \\
\hline \multicolumn{2}{|c|}{ Komponen } & Normal & Lognormal & Eksponensial & Weibull \\
\hline \multirow{2}{*}{$\begin{array}{c}\text { Clip } \\
\text { Conveyor }\end{array}$} & TTF & 0,976 & 0,982 & 0,971 & 0,992 \\
\cline { 2 - 6 } & TTR & 0,994 & 0,994 & 0,924 & 0,979 \\
\hline $\begin{array}{c}\text { Penyangga } \\
\text { Pisau }\end{array}$ & TTF & 0,954 & 0,949 & 0,985 & 0,976 \\
\cline { 2 - 6 } & TTR & 0,893 & 0,956 & 0,972 & 0,906 \\
\hline $\begin{array}{c}\text { Looper } \\
\text { Jahit }\end{array}$ & TTF & 0,947 & 0,990 & 0,985 & 0,983 \\
\cline { 2 - 6 } & TTR & 0,863 & 0,930 & 0,979 & 0,839 \\
\hline
\end{tabular}




\section{Uji Kecocokan Distribusi (Goodness of Fit Test) TTF dan TTR}

Perhitungan goodness of fit test bertujuan untuk mengetahui distribusi data TTF dan TTR yang akan berpengaruh terhadap perhitungan parameter MTTF dan MTTR. Goodness of fit test dilakukan untuk keempat distribusi kerusakan. Distribusi normal dan lognormal menggunakan uji Kolmogorov-Smirnov, distribusi eksponensial menggunakan uji Barlett, dan distribusi Weibull menggunakan uji Mann. Adapun rekapitulasi perhitungan goodness of fit TTF dan TTR komponen clip conveyor, penyangga pisau dan looper jahit ditunjukkan pada Tabel 5.

Tabel 5. Rekapitulasi Goodness Of Fit Test TTF dan TTR

\begin{tabular}{|c|c|c|c|c|}
\hline \multirow{2}{*}{ Komponen } & \multicolumn{2}{|c|}{ TTF } & \multicolumn{2}{c|}{ TTR } \\
\cline { 2 - 5 } & Distribusi & $r$ & Distribusi & $r$ \\
\hline Clip Conveyor & Weibull & 0,992 & Weibull & 0,979 \\
\hline Penyangga Pisau & Weibull & 0,976 & Weibull & 0,906 \\
\hline Looper Jahit & Weibull & 0,983 & Weibull & 0,839 \\
\hline
\end{tabular}

\section{Perhitungan MTTF dan MTTR}

Berdasarkan Tabel 5, distribusi Weibull merupakan distribusi yang terpilih. Maka, parameter yang digunakan untuk menghitung MTTF dan MTTR adalah parameter bentuk $(\beta)$ dan parameter skala $(\theta)$. Tabel 6. menunjukkan rekapitulasi perhitungan MTTF dan MTTR komponen clip conveyor, penyangga pisau, dan looper jahit.

Tabel 6. Rekapitulasi Perhitungan MTTF dan MTTR

\begin{tabular}{|c|c|c|c|c|}
\hline Komponen & $\begin{array}{c}\text { Parameter } \\
\text { MTTF }\end{array}$ & $\begin{array}{c}\text { MTTF } \\
\text { (jam) }\end{array}$ & $\begin{array}{c}\text { Parameter } \\
\text { MTTR }\end{array}$ & $\begin{array}{c}\text { MTTR } \\
\text { (jam) }\end{array}$ \\
\hline Clip Conveyor & $\begin{array}{c}\beta=2,176 \\
\theta=254,927\end{array}$ & 225,763 & $\begin{array}{c}\beta=2,879 \\
\theta=1,265\end{array}$ & 1,127 \\
\hline Penyangga Pisau & $\begin{array}{c}\beta=1,773 \\
\theta=262,989\end{array}$ & 233,966 & $\begin{array}{c}\beta=4,562 \\
\theta=0,332\end{array}$ & 0,303 \\
\hline Looper Jahit & $\begin{array}{c}\beta=2,175 \\
\theta=297,250\end{array}$ & 263,244 & $\begin{array}{c}\beta=3,641 \\
\theta=0,245\end{array}$ & 0,221 \\
\hline
\end{tabular}

\section{Prediksi Downtime Setelah Penerapan Planned Maintenance}

Melalui keandalan masing-masing komponen pada Tabel 7, maka dapat diketahui ketidakandalannya. Downtime dipengaruhi oleh persentase ketidakandalan. Semakin tinggi persentase ketidakandalan maka downtime akan semakin meningkat. Hal ini dapat disimpulkan bahwa ketidakandalan berbanding lurus dengan downtime. Prediksi dilakukan berdasarkan ketidakandalan komponen dengan asumsi penggunaan mesin sebelum dan setelah perbaikan sama. Tabel 8 menunjukkan perbandingan downtime sebelum dan setelah penerapan planned maintenance.

Tabel 8. Perbandingan Downtime Sebelum dan Setelah Planned Maintenance

\begin{tabular}{|c|c|c|c|}
\hline \multirow{2}{*}{ Nama Komponen } & \multicolumn{3}{|c|}{ Downtime (jam) } \\
\cline { 2 - 4 } & Saat Ini & Perbaikan & Selisih \\
\hline Clip Conveyor & 104,02 & 19,41 & 84,61 \\
\hline Penyangga Pisau & 47,55 & 8,55 & 39,00 \\
\hline Looper Jahit & 33,05 & 6,17 & 26,88 \\
\hline
\end{tabular}




\section{Perhitungan Biaya Pemeliharaan}

Biaya pemeliharaan dihitung berdasarkan pemeliharaan kondisi saat ini dan setelah penerapan planned maintenance. Kegiatan pemeliharaan tentu akan menimbulkan production loss yang disebabkan karena mesin berhenti ketika sedang diperbaiki. Pada perhitungan biaya ini diasumsikan bahwa setiap terjadi kerusakan akan dilakukan penggantian komponen. Biaya pemeliharaan dipengaruhi oleh biaya teknisi, biaya production loss, harga komponen, waktu MTTR, waktu perbaikan setelah planned maintenance, dan frekuensi pemeliharaan. Biaya pemeliharaan dihitung untuk tiga bulan, yaitu Januari sampai Maret. Total biaya pemeliharaan untuk kondisi saat ini (existing) ditunjukkan pada Tabel 9.

Tabel 9. Total Biaya Pemeliharaan Kondisi Saat Ini

\begin{tabular}{|c|c|c|c|}
\hline Bulan & $\begin{array}{c}\text { Biaya } \\
\text { Pemeliharaan }\end{array}$ & $\begin{array}{c}\text { Biaya Production } \\
\text { Loss }\end{array}$ & $\begin{array}{c}\text { Total Biaya } \\
\text { Pemeliharaan }\end{array}$ \\
\hline Januari & Rp25.799.220 & & \\
\hline Februari & Rp20.876.496 & \multirow{2}{*}{ Rp125.842.500 } & Rp207.963.924 \\
\hline Maret & Rp35.445.708 & & \\
\hline
\end{tabular}

Perhitungan biaya pemeliharaan setelah planned maintenance dilakukan dengan empat skenario, yaitu pemeliharaan secara terpisah berdasarkan interval pemeliharaan masing-masing komponen (skenario 1), pemeliharaan bersama dengan interval waktu 72 jam (skenario 2), pemeliharaan bersama dengan interval waktu 90 jam (skenario 3), dan pemeliharaan bersama dengan interval waktu 105 jam (skenario 4). Pada saat pemeliharaan dilakukan, terdapat waktu pemeliharaan yang bertepatan dengan jam istirahat, sehingga biaya production loss akibat downtime pemeliharaan tidak dilibatkan. Adapun perbandingan total biaya pemeliharaan berdasarkan empat skenario yang telah dibuat ditunjukkan pada Tabel 10.

Tabel 10. Perbandingan Total Biaya Pemeliharaan Setelah Planned Maintenance

\begin{tabular}{|c|c|c|c|}
\hline Total Biaya & Total Biaya & Total Biaya & Total Biaya \\
Pemeliharaan & Pemeliharaan & Pemeliharaan & Pemeliharaan \\
Skenario 1 & Skenario 2 & Skenario 3 & Skenario 4 \\
\hline Rp181.782.000 & Rp207.036.000 & Rp169.423.505 & Rp91.808.815 \\
\hline
\end{tabular}

Merujuk pada Tabel 10, diketahui bahwa skenario 4 menghasilkan total biaya pemeliharaan terkecil, yaitu sebesar Rp91.808.815. Maka, skenario 4 dipilih sebagai usulan rencana pemeliharaan mesin untuk diterapkan di perusahaan. Kesimpulan

Berdasarkan penelitian yang dilakukan dengan memberikan usulan interval pemeliharaan menggunakan pendekatan planned maintenance, maka dapat diambil kesimpulan, diantaranya:

1. Pada mesin MOJ-3 terdapat delapan komponen yang mengalami kerusakan sehingga mengakibatkan downtime, yaitu clip conveyor, penyangga pisau, looper jahit, roller cutter, rolling pin, conveyor, sensor ukuran dan sensor gulungan. Berdasarkan delapan komponen tersebut, dipilih tiga komponen yang memiliki frekuensi kerusakan tertinggi untuk dibuat interval pemeliharaan, yaitu komponen clip conveyor, penyangga pisau dan looper jahit.

2. Interval pemeliharaan yang ditentukan untuk mereduksi downtime pada mesin MOJ-3 yaitu untuk komponen clip conveyor sebesar 90 jam, komponen penyangga pisau sebesar 72 jam dan komponen looper jahit sebesar 105 jam.

3. Kondisi saat ini (existing) menunjukkan bahwa komponen clip conveyor memiliki downtime sebesar 104,02 jam, komponen penyangga pisau sebesar 47,55 jam dan komponen looper jahit sebesar 33,05 jam. Prediksi downtime yang dihasilkan setelah melakukan pemeliharaan sesuai jadwal yang diusulkan yaitu 19,41 jam untuk komponen clip conveyor, 8,55 jam untuk komponen penyangga pisau dan 6,17 jam untuk komponen looper jahit. 
4. Terdapat empat skenario pemeliharaan yang diusulkan, yaitu:

- Skenario 1 (pemeliharaan terpisah) dengan melakukan pemeliharaan sesuai dengan interval yang diusulkan. Total biaya yang dihasilkan sebesar Rp181.782.000.

- Skenario 2 (pemeliharaan bersama dengan interval waktu 72 jam) sesuai dengan jadwal pemeliharaan komponen penyangga pisau. Total biaya yang dihasilkan sebesar Rp207.036.000.

- Skenario 3 (pemeliharaan bersama dengan interval waktu 90 jam) sesuai dengan jadwal pemeliharaan komponen clip conveyor. Total biaya yang dihasilkan sebesar Rp169.423.505.

- Skenario 4 (pemeliharaan bersama dengan interval waktu 105 jam) sesuai dengan jadwal pemeliharaan komponen looper jahit. Total biaya yang dihasilkan sebesar Rp91.808.815.

5. Sebelum menerapkan planned maintenance, total biaya pemeliharaan yang dihasilkan sebesar Rp207.963.924. Dengan penerapan planned maintenance, diketahui bahwa seluruh alternatif skenario yang dibuat menghasilkan biaya pemeliharaan yang lebih rendah dibandingkan sebelum planned maintenance. Rencana pemeliharaan mesin yang diusulkan untuk diterapkan di perusahaan yaitu skenario 4 (pemeliharaan bersama dengan interval waktu 105 jam) dengan total biaya sebesar Rp91.808.815.

\section{Acknowledge}

Terima kasih kepada kedua orang tua, dosen pembimbing, dan seluruh pihak yang telah memberikan ilmu, dukungan, dan doa kepada penulis hingga penelitian ini dapat terlaksana dan diselesaikan dengan baik. Semoga penelitian ini dapat bermanfaat bagi penulis maupun para pembaca.

\section{Daftar Pustaka}

[1] Agustiady, T. K., dan Cudney, E. A., 2016. Total Productive Maintenance: Strategies and Implementation Guide [e-book] CRC Press. Tersedia pada: <http://library.lol/main/CFE96891E04A428406C67B2FFF5D2D12> [Diakses 15 Juni 2021].

[2] Asisco, H., Amar, K., Perdana, Y. R., 2012. Usulan Perencanaan Perawatan Mesin Dengan Metode Reliability Centered Maintenance (RCM) Di PT. Perkebunan Nuasntara VII (Persero) Unit Usaha Sungai Niru Kab. Muara Enim. Jurnal Sains dan Teknologi, [online] Vol. 8 No. 2., 78-98. Tersedia pada: <https://digilib.uin-suka.ac.id/id/eprint/18716/> [Diakses 8 April 2020].

[3] Dhillon, B. S., 2002. Engineering Maintenance: A Modern Approach. Florida: CRC Press.

[4] Ebeling, C. E., 2019. An Introduction to Reliability and Maintainability Engineering. New York: McGraw-Hill.

[5] Heizer, J. dan Render, B. 2011. Operation Management. [e-book] Prentice Hall: New Jersey. Tersedia pada: <http://library.lol/main/43B97088A91E0734021B2A93 7951132C> [Diakses 3 Maret 2021].

[6] Picknell, J. V. R., dan Sifonte, J. R., 2017. Reliability Centered Maintenance-Reengineered: Practical Optimization of the RCM Process with RCM-R. New York: CRC Press.

[7] Rachman, H., Garside, A. K., Kholik, H. M., 2017. Usulan Perawatan Sistem Boiler dengan Metode Reliability Centered Maintenance (RCM). Jurnal Teknik Industri, [online] Vol. 18 No. $\quad 01$. Tersedia pada: <https://ejournal.umm.ac.id/index. php/industri/article/view/4614> [Diakses 7 April 2020].

[8] Rahmawati, I., 2007. Penentuan Interval Penggantian Komponen Secara Preventif Untuk Meminimumkan Total Biaya Penggantian Penggantian Akibat Kerusakan Mesin (Studi Kasus: PT. GE Lighting Indonesia). S1. Surakarta: Universitas Sebelas Maret. Tersedia pada: $<$ https://digilib.uns.ac.id/dokumen/detail/5492/

Penentuan-interval-penggantian-komponen-secara-preventif-untuk-meminimum kan-total-biaya-penggantian-akibat-kerusakan-mesin> [Diakses 3 Desember 2020]. 
[9] Ruchiyat, I., Prasetyaningsih, E., dan Muhammad, C. R., 2020. Penentuan Interval Waktu Perawatan Mesin Blowing dan Mesin Filling Menggunakan Teori Reliability dan Model Age Replacement (Studi Kasus: PT. XYZ). Jurnal Sistem Teknik Industri, [online] Vol. 22 No. 02. Tersedia pada: <https://talenta.usu.ac.id/jsti/article/view/3762> [Diakses 19 September 2020].

[10] Soesetyo, I., dan Bendatu, L. Y., 2014. Penjadwalan Predictive Maintenance dan Biaya Perawatan Mesin Pallet Di PT. Charoen Pokphand Indonesia - Sepanjang, Jurnal Titra, [online] Vol 2, No. 2. Tersedia pada: <http://publication.petra.ac. id/index.php/teknikindustri/article/view/2352> [Diakses 19 Mei 2021]. 